\title{
The Dynamics of Trade Liberalization and Economic Growth of Ethiopia: A Vector Error Correction (VEC) Model Approach
}

\author{
Teshome Hailemeskel Abebe \\ Department of Economics, Ambo University, Ambo, Ethiopia \\ Email address: \\ teshome251990@gmail.com \\ To cite this article: \\ Teshome Hailemeskel Abebe. The Dynamics of Trade Liberalization and Economic Growth of Ethiopia: A Vector Error Correction (VEC) \\ Model Approach. International Journal of Economic Behavior and Organization. Vol. 8, No. 4, 2020, pp. 81-91. \\ doi: $10.11648 /$ j.ijebo.20200804.11
}

Received: October 27, 2020; Accepted: November 21, 2020; Published: December 8, 2020

\begin{abstract}
Economic growth is one of the primary goals of developing countries like Ethiopia. Hence, investigating the causes of economic growth in such country is of great importance. Thus, in this study, the impact of trade openness on economic growth of Ethiopia from 1982 to 2019 on data obtained from World Bank (WB) database were investigated. The methodology employed in this study is vector error correction model (VECM). A Unit root test was carried out using the ADF and PP tests. From unit root results, all series are non-stationary at levels. The first differences of all series, however, were found to be stationary. For the study period, there was one co-integrating relationship. The estimated long run model shows the existence of strong positive long-run relationship between trade openness and economic growth. The Block Exogeneity Wald Tests result shows a one-way causality running from trade openness to economic growth. The estimated coefficient of the error correction term $(\alpha=-0.702)$ is negative and statistically significant at the one percent level, indicating about $70.2 \%$ of the short run disequilibrium in economic growth will be adjusted within a year (the same year). Moreover, in the short run, one-time lagged trade openness has a significant positive impact on the current growth rate of real GDP. Furthermore, the model diagnostic result shows non-autocorrelation and normal residuals
\end{abstract}

Keywords: Economic Growth, Trade Openness, Unit Root, Co-integration, Vector Error Correction Model

\section{Background of the Study}

Economic growth is one of the primary goals of developing countries and is the main issue of planners and policy makers and hence investigating the causes of economic growth is of great importance from macroeconomic point of view. Macroeconomic relationship between trade liberalization and economic growth has always been of interest to economists. However, the relationship between liberalization and economic growth is a controversial topic from theoretical as well as empirical point of view.

Theoretically, the argument that trade openness promote economic growth goes back to early work of famous Adam Smith in his idea about market specialization. It finds support for the endogenous growth theory associated with Romer study [1]. The benefits from trade liberalization might be realized through first, openness promotes the efficient allocation of resources; second, allows the dissemination of knowledge and technological advancement; third, stimulates competition in domestic and international markets; and fourth, increases returns to scale. Moreover, Bhagwati argues that a liberal trade strategy is beneficial to developing countries because it would bring efficiency in resource allocation, eliminate directly unproductive profit seeking and rent seeking activities, encourage foreign investment, and stimulate dynamic positive effects on the domestic economy [2]. On the other hand, Dornbusch and Rodriguez argue that protection can raise income, but when the economy is less than full employment $[3,4]$. Moreover, Singer and Prebisch provided justification for a protectionist policy by considering the division of world into a 'center', the developed countries, and a 'periphery', the developing world, where trade acted as a source of impoverishment in the latter and as a source of enrichment in the former. According to these theories, trade brings growth for the industrialized countries with little or no gain at all for the developing countries [5, 6].

Empirically, Thirlwall generalized trade liberalization in form of unilateral tariff reductions or the reduction of non-tariff 
barriers to trade to improves growth performance [7]. Moreover, Manni and Afzal stated that trade liberalization policies open up the opportunity for countries' economies to enhance growth and foster overall development [8]. On the contrary, Alam et. al., investigate that trade liberalization can negatively relate with growth since trade liberalization enhance production intensity in developing countries and this may prompt more industrial contamination and environmental degradation [9]. Mukhopadhyay \& Chakraborty support the negative arguments of liberalization by stating, as liberalized trade regimes provide incentives for export; it will lead to a greater misuse of natural resources resulting in environmental degradation [10].

Beside the above theoretical and empirical arguments many international institutions (like World Bank, the International Monetary Fund and the Organization for Economic Cooperation and Development) believe that trade openness will lead to better and faster economic growth.

In this regard, following the Washington consensus, many developing countries, including Ethiopia try to liberalize the foreign sector. The government of Ethiopia had been conducting trade reform which include reduction of trade barriers and opening of international trade to foreign competition in 1992 following the structural adjustment program (SAP) with the help of international monetary fund (IMF) and World Bank (WB) even though failed to attain the desired change. Consequently, various works have been done on the economic impact of trade liberalization on economic growth of Ethiopia. In this regard, Zewdu and Minyahil study the nexus of economic growth and trade liberalization in Ethiopia using Johnson's multivariate co-integration analysis over the data ranging from 1974/75-2014/15. The test results suggest the existence of positive and significant impact of trade liberalization on economic growth in Ethiopia [11].

Generally, as explained above, some researchers deduce and found a positive relationship between the subjects and some identifies and have found an inverse or no relationship between trade liberalization and economic growth. In this regard, Salinas and Aksoy says that there is yet no conclusive evidence about the economic impact of trade liberalization on economic growth of countries [12]. Therefore, despite the existence of extensive literature in this regard, yet no clear and definitive answer on this issue exist. Hence, in this study, the researcher is motivated to contribute to the existing gap in the literature and practice on international trade by examines the effect of trade liberalization on economic growth in Ethiopia using a VEC modeling approach given into consideration the spanning period of the study.

The remaining part of the paper is organized as follows. Section 2 presents the general methodology of the paper. Section 3 presents the data, results, and discussion. Section 4 presents conclusions and recommendations.

\section{Methodology}

\subsection{Variables}

Trade liberalization is an indication of the share of international transactions relative to domestic transactions. It can measured using proxy variable, trade openness that is exports plus imports divided by GDP, used by a large number of studies.

Mathematically, trade openness as a measure of liberalization is defined as:

$$
\text { Trade openness }=\frac{\text { Export }+ \text { Import }}{G D P}
$$

Economic Growth (Growth of real GDP): -it refers to an increasing in the amount of goods and services produced by an economy over time. In this case, the annual growth rate of real GDP is used as a measure of economic growth.

$$
\text { Economic growth }(g G D P)=\frac{g G D P_{t}-g G D P_{t-1}}{g G D P_{t-1}} \times 100 \%
$$

where $g G D P_{t}$ is growth rate of real GDP at time t, and $g G D P_{t-1}$ is growth rate of real GDP in the previous year.

\subsection{Unit Root Test}

Stationarity of a series is an important phenomenon because it can influence its behavior. If $x$ and $y$ series are nonstationary random processes (integrated), then modeling $x$ and $y$ relationship as a simple OLS relationship will only generate a spurious regression. Moreover, if the series are non-stationary, then there is no a tendency to return into a constant value or linear trend. If a series is stationary without any differencing it is designated as integrated of order $I(0)$. On the other hand, a series that has stationary first differences is integrated of order one $I(1)$. To test the existence of a unit root problems (nonstationary) in the time series, the Augmented Dickey Fuller and Phillips Perron unit root tests were applied.

\subsubsection{Augmented Dickey Fuller Test}

In conducting, the dickey fuller test assumed that the error term was uncorrelated.

Consider the AR (1) series

$$
y_{t}=\phi y_{t-1}+\varepsilon_{t}
$$

If the coefficient $\phi$ is $-1<\phi<1$, then $y_{t}$ is stationary. If the coefficient $\phi=1$, then $y_{t}$ is non-stationary. Therefore, the unit root hypotheses are given by:

$$
H_{o}: \phi=1 \text { and } H_{1}: \phi<1
$$

Then subtract $y_{t-1}$ from the above equation results:

$$
\begin{gathered}
y_{t}-y_{t-1}=\phi y_{t-1}-y_{t-1}+\varepsilon_{t} \\
\Delta y_{t}=(\phi-1) y_{t-1}+\varepsilon_{t}
\end{gathered}
$$

The standard Dickey-Fuller test, after subtraction of $y_{t-1}$ become:

$$
\Delta y_{t}=\delta y_{t-1}+\varepsilon_{t}
$$

where $\phi-1=\delta$.

Thus, testing for $\phi=1$ is equivalent to testing for $\delta=0$

Then conventional t-ratio:

$$
t_{\delta}=\frac{\widehat{\delta}}{s . e(\widehat{\delta})}
$$


where $\hat{\delta}$ is the estimate of $\delta$, and s. $e(\hat{\delta})$ is the standard error of $\hat{\delta}$.

However, in the case of correlated error, Dickey and Fuller have developed a test known as the Augmented Dickey Fuller (ADF) test. This test would be conducted by augmenting the equation by adding the lagged difference term of the dependent variable to the right-hand side of the test regression. The number of lagged difference terms to include is often determined empirically, the idea being to include enough terms so that the error term is serially uncorrelated. If the data is not stationary at level, we take first difference, second difference and so on until it became stationary. A time series data is said to be stationary if the calculated $\mathrm{ADF}$ is greater than the critical $\mathrm{ADF}$ at a given level [13].

The Augmented Dickey Fuller (ADF) test statistic for a pure random walk model (a time series that has a unit root or non-stationary time series) can be specified as:

$$
\Delta y_{t}=\delta y_{t-1}+\sum_{i=1}^{p} \gamma_{i} \Delta y_{t-i}+\varepsilon_{t}
$$

The Augmented Dickey Fuller (ADF) test statistic contains an intercept (drift) term

$$
\Delta y_{t}=\alpha+\delta y_{t-1}+\sum_{i=1}^{p} \gamma_{i} \Delta y_{t-i}+\varepsilon_{t}
$$

The Augmented Dickey Fuller (ADF) test statistic with both the drift and linear time trend

$$
\Delta y_{t}=\alpha+\eta_{1} \tau_{t}+\delta y_{t-1}+\sum_{i=1}^{p} \gamma_{i} \Delta y_{t-i}+\varepsilon_{t}
$$

where $\alpha$ is a constant term, $\tau_{t}$ is a deterministic trend, $\eta_{1}$ is the trend coefficient, $\Delta y_{t-1}=y_{t-1}-y_{t-2}, \Delta y_{t-2}=y_{t-2}-$ $y_{t-3}, \ldots \Delta y_{t-n}=y_{t-n}-y_{t-(n-1)}, p$ are the lag terms, and $\varepsilon_{t}$ is white noise error term.

The null and alternative hypotheses tests are given by:

$H_{o}: \delta=0$; the series has a unit root or non-stationarity

$H_{1}: \delta<0$; the series has not a unit root or Stationarity

If the computed t-statistic (in absolute terms) exceeds the ADF critical values, we reject the null indicating the series are stationary.

\subsubsection{The Phillips-Perron (PP) Test}

Phillips and Perron propose a nonparametric method of controlling for higher order serial correlation in testing for a unit root [14].

The PP method estimates the original DF test equation and modifies the t -ratio of $\boldsymbol{\delta}$ coefficient so that serial correlation does not affect the asymptotic distribution of the test statistic.

The PP test is based on the statistic:

$$
\hat{t}_{\delta}=t_{\delta}\left(\frac{\gamma_{0}}{f_{0}}\right)^{1 / 2}-\frac{T\left(f_{0}-\gamma_{0}\right)(s \cdot e(\widehat{\delta}))}{2 f_{0}{ }^{1 / 2} * s}
$$

where $\hat{\delta}$ is the estimate of $\delta, t_{\delta}$ is the t-ratio, s.e $(\hat{\delta})$ is the standard error of $\hat{\delta}$ and $s$ is the standard deviation of the test regression. In addition, $\gamma_{0}$ is a consistent estimate of the error variance in DF equation calculated as $(T-n) \frac{s^{2}}{T}$, where $\mathrm{n}$ is the number of regressors. The remaining term $f_{0}$ is an estimator of the residuals spectrum at frequency zero. The asymptotic distribution of the PP modified t-ratio is the same as the ADF statistic.

\subsection{Vector Autoregressive Models (VAR)}

Vector auto regression (VAR) is a stochastic process model is used to capture the linear interdependencies among multiple time series. VAR models generalize the univariate autoregressive (AR model) by allowing more than one evolving variable. All variables in a VAR inter the model in the same way: each variable has an equation explaining its evolution based on its own lagged values, the lagged values of the other variables, and error term.

Suppose that we measure two difference time series variables, say $y_{t 1}$ as a measure of economic growth and $y_{t 2}$ as a measure of trade openness, then a two variable VAR model for order 1, VAR(1) is as follows:

$$
\begin{aligned}
& y_{1, t}=c_{1}+\Phi_{1,1} y_{1, t-1}+\Phi_{1,2} y_{2, t-1}+\varepsilon_{1, t} \\
& y_{2, t}=c_{2}+\Phi_{2,1} y_{1, t-1}+\Phi_{2,2} y_{2, t-1}+\varepsilon_{2, t}
\end{aligned}
$$

The above model can be written in matrix form as follows:

$$
\left[\begin{array}{l}
y_{t, 1} \\
y_{t, 2}
\end{array}\right]=\left[\begin{array}{l}
c_{1} \\
c_{2}
\end{array}\right]+\left[\begin{array}{ll}
\Phi_{1,1} & \Phi_{1,2} \\
\Phi_{2,1} & \Phi_{2,2}
\end{array}\right]\left[\begin{array}{l}
y_{1, t-1} \\
y_{2, t-1}
\end{array}\right]+\left[\begin{array}{l}
\varepsilon_{1, t} \\
\varepsilon_{2, t}
\end{array}\right]
$$

Each variable is a linear function of the lag 1 value for all variables in the set.

In general, the VAR (p) model is given by:

$$
Y_{t}=c+\sum_{i=1}^{p} \Phi_{i} Y_{t-i}+\varepsilon_{t}
$$

where $Y_{t}=\left(y_{1 t}, y_{2 t}, \ldots, y_{k t}\right)^{\prime}$ is a $k \times 1$ random vector of endogenous variables, $\mathrm{i}=1,2, \ldots . \mathrm{p} \quad \& \mathrm{t}=1,2, . ., \mathrm{T}, \quad c=$ $\left(c_{1}, c_{2}, \ldots, c_{k}\right)^{\prime}$ is a fixed $k \times 1$ vector of intercept term, $p$ is the length of lag, $\Phi_{i}$ are a fixed $k \times k$ coefficient matrices. Finally, $\varepsilon_{t}=\left(\varepsilon_{1}, \varepsilon_{2}, \ldots, \varepsilon_{k}\right)^{\prime}$ is a $k \times 1$ white noise error term given that, $E\left(\varepsilon_{t}\right)=0, E\left(\varepsilon_{t}, \varepsilon_{t}{ }^{\prime}\right)=\Sigma_{\varepsilon}$ and $E\left(\varepsilon_{t}, \varepsilon_{s}^{\prime}\right)=$ 0 , for $\forall t \neq s$.

The VAR model is considered if the variables or series are stationary; that is, they are $\mathrm{I}(0)$ series.

\subsection{The Optimal Lags Length Selection}

It is well-known in theory that the co-integration tests are very sensitive to the choice of lag length. Thus, the relevant order of lag should be specified before undertaking cointegration test. This is important since under parameterization may lead to estimation bias and over parameterization results in the loss of degrees of freedom and thus the power of the test. The lag length for the VAR (p) model may be determined using model selection criteria. The general approach is to fit VAR (p) models with orders $p=0, \ldots, p_{\max }$ and choose the value of $p$ which minimizes some modelselection criteria.

The lag lengths for the VAR (p) model have the form:

$$
I C(p)=\ln |\bar{\Sigma}(p)|+c_{T} \cdot \varphi(n, p)
$$

where $\bar{\Sigma}(p)=T^{-1} \sum_{t=1}^{T} \hat{\varepsilon}_{t} \hat{\varepsilon}_{t}{ }^{\prime}$ is the residual covariance 
matrix without a degree of freedom correction from a $\operatorname{VAR}(\mathrm{p}), c_{T}$ is a sequence indexed by the sample size $T$, and $\varphi(n, p)$ is a penalty function that penalizes large $\operatorname{VAR}(\mathrm{p})$ models. In order to select the lag length of the VAR model, Akaike Information Criterion (AIC), Bayesian Information Criterion (BIC) and Hannan-Quinn Information Criterion (HQ) are employed.

The Akaike Information Criterion (AIC)

$$
\operatorname{AIC}(p)=\ln |\bar{\Sigma}(p)|+\frac{2}{T} p n^{2}
$$

The Bayesian Information Criterion

$$
S B C(p)=\ln |\bar{\Sigma}(p)|+\frac{\ln T}{T} p n^{2}
$$

Hannan-Quinn Criterion

$$
H Q(p)=\ln |\bar{\Sigma}(p)|+\frac{2 \ln \ln T}{T} p n^{2}
$$

where $p$ is the number of lag terms in the in VAR model, $n$ is number of dependent variables and $T$ is the number of observations. The AIC criterion asymptotically overestimates the order with positive probability, whereas the BIC and HQ criteria estimate the order consistently under fairly general conditions if the true order $\mathrm{p}$ is less than or equal to pmax.

\subsection{Testing for Cointegration}

Cointegration is the statistical analog commonly used to examine the existence of long-run relations between one or more time series. The basic idea behind cointegration is that if in the long-run two or more time series variables move closely together, even though the series themselves are trended, the difference between them is constant. It is possible to regard these variables as defining a long-run equilibrium relationship, as the difference between them is stationary [15]. On the other hand, the absence of cointegration implies that there is no long-run relationship between the variables.

Johansen and Juselius Co-integration Test

Johansen and Juselius test of cointegration procedures uses two tests to determine the number of cointegration vectors: the Maximum Eigenvalue test and the Trace test. Both the Trace and maximum Eigenvalue tests were used under the null hypothesis of no cointegrating vector. For both tests, if the test statistic value is greater than the critical value, the null hypothesis of $r$ cointegrating vectors is rejected in favor of the corresponding alternative hypothesis [16].

Let us consider a two variable system with one cointegrating equation and no lagged difference terms, and then the cointegrating equation is:

$$
y_{2,1}=\beta y_{1, t}
$$

The corresponding VEC model is:

$$
\begin{aligned}
& \Delta y_{1, t}=\alpha_{1}\left(y_{2, t-1}-\beta y_{1, t-1}\right)+\varepsilon_{1, t} \\
& \Delta y_{2, t}=\alpha_{2}\left(y_{2, t-1}-\beta y_{1, t-1}\right)+\varepsilon_{2, t}
\end{aligned}
$$

The general $y_{t}$ cointegration relationship of the vector error correction representation of the form (given $y_{t}=$ $\left.y_{t-1}+\Delta y_{t}\right)$ in line with ref. [17] as below:

$$
\Delta y_{t}=\mathrm{c}+\pi y_{t-1}+\sum_{i=1}^{p-1} \Gamma_{i} \Delta y_{t-i}+\varepsilon_{t}
$$

where $\Delta$ is difference operator (e.g., $\Delta y_{t-1}=y_{t}-y_{t-1}$ )

$$
\begin{gathered}
\Gamma_{i}=-\left(\Phi_{i+1}+\ldots+\Phi_{p}\right)=-\sum_{i=j+1}^{p} \Phi_{i}, i=1, \ldots, p-1 \\
\pi=\sum_{i=1}^{p} \Phi_{i}-I
\end{gathered}
$$

The characteristic polynomial is $I-\tau_{1} Z-\cdots-\tau_{p} z^{p}=$ $\tau(\mathrm{z}), \varepsilon_{t}=\left(\varepsilon_{1 t}, \ldots, \varepsilon_{p t}\right)^{\prime}$ is a vector of white noise process with $\varepsilon_{t} \sim\left(0, \sum_{\varepsilon}\right)[18,19]$.

For cointegration $(I(1))$ to hold the matrix $\pi$ must have reduced rank $(0 \leq r<k)$, where $\mathrm{r}$ is the number of linearly independent cointegrating vectors and $\mathrm{K}$ is the number of variables. In the general case of $\mathrm{K}$ variables, there may be 1 , $2, \ldots,(\mathrm{K}-1)$ cointegrating vectors representing stationary linear combinations.

In case of VAR model, there might be three commonly specifications depend on the rank conditions. If $\pi$ has full rank ( $\operatorname{rank} \pi=k)$, all of the variables in $y_{t}$ are $\mathrm{I}(0)$ and a VAR in their levels is consistently used. If $\pi$ has zero rank (rank $\pi=0$ ), here is no cointegration among the nonstationary variables, and a VAR in their first differences is consistent. However, if the rank of $\pi$ is $r$ (i.e. $0<r<k$ ), then we have cointegration and this is the main interest of VEC model.

The matrix coefficient of cointegration $\pi=\alpha \beta^{\prime}$ (thus $\pi$ is decomposed into two matrices of dimensions $[K \times r]$, and $\mathrm{r}$ is the number of cointegration vectors. Where $\alpha$ is a matrix of rank $r$ adjustment coefficients or the loading matrix and is the response speed of the last period's deviation from equilibrium level while $\beta$ is matrix of rank $r$ long run equilibrium relationship or long run coefficients (cointegrating vector) and refers to columns of a matrix of linearly independent cointegrating vectors. $\beta^{\prime} y_{t-1}=e c m_{t-1}$ is error correction term.

Johansen and Juselius specify two likelihood ratio test statistic to test for the number of cointegrating vectors. The first likelihood ratio statistic tests for the null hypothesis of exactly $r$ cointegrating vectors against the alternative $r+1$ vectors is the maximum eigenvalue statistic.

Specifically, the null and alternative hypotheses under maximum eigenvalue test:

$H_{0}: \operatorname{Rank}(\pi)=r$ against $H_{1}: \operatorname{Rank}(\pi)=r+1$

The Maximum Eigenvalue test statistic is computed as:

$$
\lambda_{\text {max }}(r, r+1)=-T * \ln \left(1-\hat{\lambda}_{r+1}\right)
$$

The second statistic tests is trace statistic for at most $r$ number of distinct cointegrating vectors against the alternative of $r+1$ cointegrating relationship. Critical values for both test statistics are tabulated in Johansen-Juselius. Specifically, the null and alternative hypotheses under Trace test:

$H_{0}: \operatorname{Rank}(\pi) \geq r$ against $H_{1}: \operatorname{Rank}(\pi)=r+1$

The Maximum trace test statistic is given by: 


$$
\operatorname{Tr}(r)=-T \sum_{i=r+1}^{k} \ln \left(1-\hat{\lambda}_{i}\right)
$$

where $\mathrm{k}$ is the number of endogenous variables in the system, $\hat{\lambda}$ is the estimated eigenvalue ofthe characterstic roots, and and $\mathrm{T}$ is the sample size.

This test starts from $r=0$ and up to the first time we note that the null hypothesis is not rejected. Rank cointegration is found from the value of $r$. If the absolute value of the computed trace statistic is greater than its critical value, then we reject our null hypothesis of no cointegration and claim that there exists at least one-way cointegration relation between the variables. In some cases, Trace and Maximum Eigen value statistics yield different results. In that case, in some cases Trace and Maximum Eigenvalue statistics may yield different results and Alexander, C. indicates that in this case the results of trace test should be preferred [20].

\subsection{Granger Causality Tests}

Granger Causality test examines whether lagged values of one variable helps to predict another variable. It is the $\mathrm{F}$ statistic testing the hypothesis that the coefficients on all the values of one variables in the above equation (for example the coefficients on are zero). Many researchers in the field of Time Series Econometrics have used Granger causality procedure to study the causal interactions that exists among economic indicators in various countries of the world. Moreover, several articles have surfaced in literature on the use of Granger causality tests to analyze time series data since its introduction by Granger [21].

Granger Causality specification for testing the causal relationship between trade openness and economic growth is given by:

$$
\begin{aligned}
& g G D P_{t}=\alpha_{0}+\sum_{i=1}^{m} \alpha_{1} g G D P_{t-i}+\sum_{i=1}^{n} \alpha_{1} O P P_{t-i}+\varepsilon_{1 t} \\
& O P P_{t}=\beta o+\sum_{i=1}^{m} \beta_{1} O P P_{t-i}+\sum_{i=1}^{n} \beta_{2} g G D P_{t-i}++\varepsilon_{2 t}
\end{aligned}
$$

\subsection{Vector Error Correction Model (VECM) Specification}

If cointegration has been detected between series we know that there exists a long-term equilibrium relationship between variables in which VECM should be applied.

A vector error correction (VEC) model is a restricted VAR designed for use with non-stationary series that are known to be cointegrated. The VEC has cointegration relations built into the specification so that it restricts the long-run behavior of the endogenous variables to converge to their cointegrating relationships while allowing for short-run adjustment dynamics. The cointegration term is known as the error correction term since the deviation from long-run equilibrium is corrected gradually through a series of partial short-run adjustments.

The general Vector Error Correction Model (VECM) specification is given by:

$$
\Delta y_{t}=c+\sum_{i=1}^{p-1} \Gamma_{i} \Delta y_{t-i}+\alpha E C M_{t-1}+\varepsilon_{t}
$$

where $\Delta$ is difference operator, $\Gamma_{i}$ are short run coefficients, $\varepsilon_{t}$ is random term. The coefficient of error correction term $(\alpha)$ measures the speed of adjustment by any deviation from the long run back to equilibrium point. A significant and negative coefficient of error correction term $\left(E C M_{t-1}\right)$ indicates convergence where as a positive coefficient shows the diverging from the long run equilibrium point. The one lag in coefficient of error correction term $\left(E C M_{t-1}\right)$ refers to whether past values of variables affect the current values.

Moreover, we can explain the causality between variables in three ways. First, through examining the significance of the lagged differences of variable in VEC model through a joint Wald or F-test, which measure short-run causality. Second by observing the significance of the t-statistic of ECT that is a measure long-run causality and finally by reviewing the joint significance of the ECT \& lagged variables in each VEC variable through a joint Wald or F-test that measure strong Granger causality.

\subsection{VEC Model Estimation}

If the variables in $y_{t}$ are not covariance stationary, but their first differences are stationary and co-integrated, estimation of the relationship between variables using vector error correction model (VECM) is essential.

\subsection{Model Adequacy Checking}

It is a standard tool to conduct a diagnostic check to identify a model before it can be used for interpreting and forecasting. Thus, in order to determine the robustness of the model, diagnostic tests should be implemented.

\subsubsection{Autocorrelation LM test}

For testing the presence of serial autocorrelation, Lagrange Multiplier test that involves regressing the squared residuals from the fitting VEC model on constant and lagged residuals of the first $p$, lags is used.

$$
\hat{\varepsilon}_{t}=\gamma_{0}+\gamma_{1} \hat{\varepsilon}_{t-1}+\gamma_{2} \hat{\varepsilon}_{t-2}+\cdots+\gamma_{p} \hat{\varepsilon}_{t-p}+v_{t}
$$

where $v_{t}$ is a white noise processfrom an auxiliary model

The null and alternative hypotheses are:

$$
\begin{gathered}
H_{0}: \gamma_{1}=\gamma_{2}=\gamma_{3}=\gamma_{p}=0 \\
H_{1}: \text { at least one } \gamma_{j} \neq 0, j=1,2, \ldots, p
\end{gathered}
$$

Denoting the residuals from the estimated auxiliary model by $\hat{v}_{t}(\mathrm{t}=1, \ldots, \mathrm{T})$, the residual covariance matrix estimator obtained from the auxiliary model is:

$$
\hat{\Sigma}_{v}=\frac{1}{T} \sum_{t=1}^{T} \hat{v}_{t} \hat{v}_{t}{ }^{\prime}
$$

Moreover, re-estimating the relevant auxiliary model without the lagged residuals $\hat{v}_{t-1}$, that is, imposing the restriction $\gamma_{1}=\gamma_{2}=\gamma_{3}=\gamma_{p}=0$, and denoting the resulting residuals by $\hat{v}_{t}{ }^{0}$, thecorresponding covariance matrix estimator is:

$$
\widehat{\Sigma}_{v 0}=\frac{1}{T} \sum_{t=1}^{T} \hat{v}_{t}{ }^{0} \hat{v}_{t}{ }^{0},
$$

The LM statistic is: 


$$
\lambda_{L M}(p)=T\left\{n-\operatorname{tr}\left[\left(\hat{\Sigma}_{v 0}\right)^{-1}\left(\hat{\Sigma}_{v}\right)\right]\right\}
$$

This statistic has an asymptotic $\mathrm{X}^{2}\left(p n^{2}\right)$ distribution under the null hypothesis and $p$ is degree of freedom. Rejecting the null hypothesis indicates the presence of autocorrelation.

\subsubsection{Test of Multivariate Normality}

The multivariate version of the Jarque Bera test is used to test the normality of the residual vector such that its components are independent and then check the compatibility of the third and fourth moments with those of a normal distribution. It is a standard tool to conduct a diagnostic check to identify a model before it can be used for forecasting. Testing for normality of residual is a test designed to determine the normality residual. The purpose of this test is to ascertain whether the residuals from the data are normally distributed or not.

Lütkepohl suggests using the multivariate generalization of the Jarque-Bera test to test the multivariate normality of the $\varepsilon_{t}$. This tests the skewness and kurtosis properties of the $\varepsilon_{t}$ $\left(3^{\text {rd }} \& 4^{\text {th }}\right.$ moments) against those of a multivariate normal distribution of the appropriate dimension [22].

The null (normality of residual) and alternative hypotheses are given by:

$$
\begin{gathered}
\mathrm{H}_{0}: E\left(\varepsilon_{t}^{s}\right)^{3}=\text { skewness } \approx 0 \text { and } E\left(\varepsilon_{t}^{s}\right)=(\text { kurtosis }) \approx 3 \\
\mathrm{H}_{1}: E\left(\varepsilon_{t}^{s}\right)^{3} \neq 0 \text { or } E\left(\varepsilon_{t}^{s}\right)^{4}>3
\end{gathered}
$$

The residual covariance matrix is estimated as: $\widehat{\sum}_{\varepsilon}=$ $\frac{1}{T} \sum_{t=1}^{T}\left(\hat{\varepsilon}_{t}-\bar{\varepsilon}\right)\left(\hat{\varepsilon}_{t}-\overline{\hat{\varepsilon}}\right)^{\prime}$

The square root of covariance matrix computed as $\left(\widehat{\Sigma}_{\varepsilon}\right)^{1 / 2}$

Now we define the standardized residuals and their sample moments

$$
\widehat{U}_{t}=\left(\widehat{\Sigma}_{\varepsilon}\right)^{1 / 2}\left(\hat{\varepsilon}_{t}-\overline{\hat{\varepsilon}}\right)
$$

The tests for non-normality based on the skewness of the standardized residuals

$$
\widehat{b}_{1}=\left(b_{11} \ldots \ldots \ldots b_{k 1}\right)^{\prime} \Rightarrow \widehat{b}_{n 1}=\frac{1}{T} \sum_{t=1}^{T} \widehat{U}^{3}{ }_{n t}
$$

The kurtosis of the standardized residuals: $\hat{b}_{2}=$ $\left(\hat{b}_{21} \ldots \ldots \ldots \ldots \hat{b}_{2 n}\right) \Rightarrow \hat{b}_{2 n}=\frac{1}{T} \sum_{t=1}^{T} \widehat{U}_{n t}^{4}$

Now skewness, $S_{3}=\frac{1}{6} T \hat{b}_{1}^{\prime} \hat{b}_{1}$ and the kurtosis, $S_{4}=$ $\frac{1}{24} T\left(\hat{b}_{2}-3\right)^{\prime}\left(\hat{b}_{2}-3\right)$

where $3=(3,3, \ldots, 3)^{\prime}$ is an $(\mathrm{n} \times 1)$ vector.

Finally a multivariate version of the Jarque-Bera statistic is:

$$
J B_{n}=S_{3}+S_{4}
$$

The statistic $S_{3}$ and $S_{4}$ have aX ${ }^{2}(\mathrm{n})$ limiting distributions and $J B$ has a $\mathrm{X}^{2}(2 \mathrm{n})$ asymptotic distribution if the normality null hypothesis holds.

\subsubsection{Stability Test}

The stability system VEC model can be from the inverse roots characteristics polynomial of AR. A VEC system is said to be stable (stationary) if all roots have a modulus of less than one and contained within the unit circle.

\section{Data, Results and Discussions}

\subsection{Data}

The annual data on import, export, and gross domestic product (GDP) of Ethiopia are obtained from World Bank (WB) database from the period 1982-2019.

\subsection{Preliminary Analysis}

\subsubsection{Graphical Analysis}

From Figure 1, we observe that, both variables (growth rate of real GDP and trade openness) generally exhibit upward trends with fluctuating behavior. Thus, from the figure we observe that variables seem to be non-stationary at level. Moreover, the graph of growth rate of real GDP does not have an intercept term, but trending, which is the nature of macroeconomic variables, while trade openness has an intercept term, as well as trending component. Therefore, in case of non-stationarity (unity root) test, we consider the time trend for Growth rate of real GDP and intercept term and time trend for trade openness.

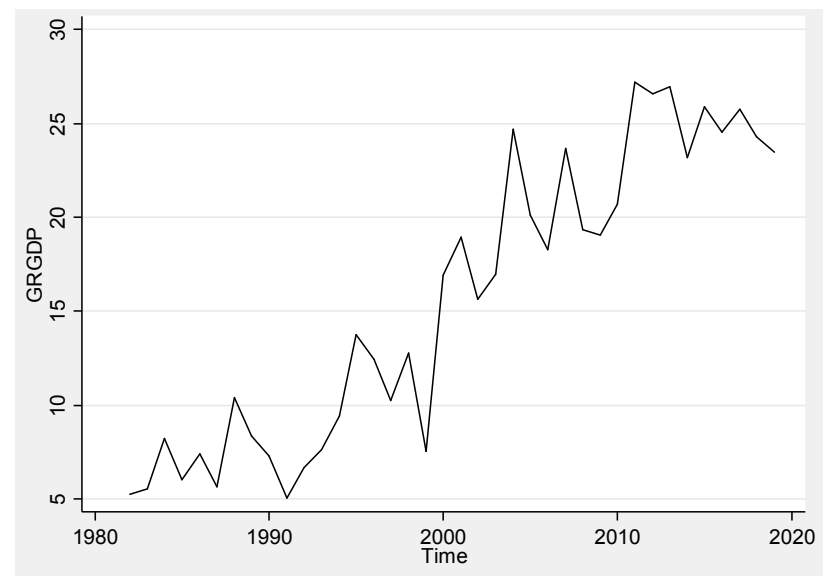

Source: Author's computation

Figure 1. Time series plots of $g G D P$.

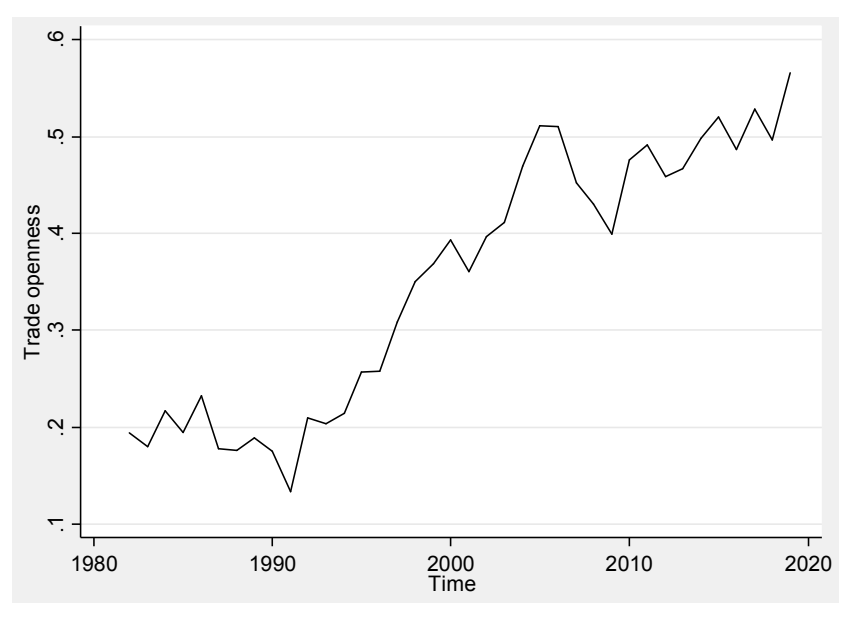

Source: Author's computation

Figure 2. Time series plots of Trade openness. 


\subsubsection{Descriptive Statistics}

Descriptive analysis is conducted to ascertain the statistical properties of the variables. Table 1 presents descriptive statistics of the variables. It should be noted that the skewness and kurtosis of a normal distribution are 0 and 3, respectively. If the Kurtosis is less than 3, the distribution is flat relative to the normal. Based on the skewness, the descriptive statistics suggest that both growth rate of real GDP and trade openness are approximately normally distributed because their respective skewness is less than 0.2 in absolute values. In addition, based on kurtosis, growth rate of real GDP tends to be mesokurtic because its value is approximately equal to 3 . Overall, it can be concluded that there is evidence that there are no outliers in these respective time series causing the data sets to become relatively symmetrical.

Table 1. Summary of test for variables.

\begin{tabular}{llllllll}
\hline Variable & Obs & Mean & Std. Dev. & Min & Max & Skewness & Kurtosis \\
\hline gGDP & 38 & 6.313669 & 6.379278 & -11.14435 & 13.85933 & -0.13924 & 2.551074 \\
Opp & 38 & .3517828 & 0.1349754 & 0.1338378 & 0.5656556 & -0.11592 & 1.46042 \\
\hline
\end{tabular}

Source: Author computation

\subsection{Unit Root Test}

As reported earlier, when time series data are not stationary and are used in an econometric equation, there is the problem of spurious regression, which leads to unreliable results. In order to avoid this problem, it is necessary to investigate the time series data for their stationary properties.

The results of both the ADF and PP tests are reported in Table 2. The findings indicate that both growth rate of real GDP and trade openness are not stationary in their level.

Table 2. Unit root test results at level.

\begin{tabular}{llllll}
\hline \multirow{2}{*}{ Variables } & \multirow{2}{*}{ Test equation } & ADF test & & PP test & \\
\cline { 3 - 5 } & & Test statistic & P-value & Test statistic & P-value \\
\hline \multirow{2}{*}{ gGDP } & With intercept & -1.914 & 0.3254 & -1.829 & 0.3661 \\
& With intercept \& trend & -2.741 & 0.2196 & -2.849 & 0.1795 \\
\multirow{2}{*}{ Openness } & With intercept & -0.451 & 0.9012 & -0.242 & 0.9333 \\
& With intercept \& trend & -2.567 & 0.2955 & -2.567 & 0.2955 \\
\hline
\end{tabular}

Source: Author computation

Note: The corresponding critical values for ADF test and PP test with constant term, and trend term are from Mackinnon (1996) constant term, respectively.

Table 3. Unit root test results at first difference.

\begin{tabular}{|c|c|c|c|c|c|}
\hline \multirow{2}{*}{ Variables } & \multirow{2}{*}{ Test equation } & \multicolumn{2}{|l|}{ ADF test } & \multicolumn{2}{|l|}{ PP test } \\
\hline & & Test statistic & P-value & Test statistic & P-value \\
\hline gGDP & With intercept & -7.631 & 0.0000 & -9.298 & 0.0000 \\
\hline \multirow{2}{*}{ Openness } & With intercept & -7.034 & 0.0000 & -9.298 & 0.0000 \\
\hline & With intercept \& trend & -4.229 & 0.0006 & -9.093 & 0.0000 \\
\hline
\end{tabular}

Source: Author computation

From the results in Table 3 we observe that all explanatory variables become stationary after first differencing, indicating that all variables are integrated order of one $I(1)$.

\subsection{Lag Length Selection}

Before we perform co-integration test, we need to determine the amount of lag that needed to be included in co- integration test and model estimations. Table 4 shows that the optimal lag length for unrestricted VAR model is two as recommended by major information criteria. Therefore, lag one is used in the Johansen cointegration analysis and Vector Error Correction Model (VECM), which is the optimal lag length minus one.

Table 4. Lag Order selection criteria results.

\begin{tabular}{lllllll}
\hline lag & LL & LR & df & P & AIC & HQIC \\
\hline$|0|$ & -216.318 & & & & 12.8422 & 12.8729 \\
$|1|$ & -189.064 & 54.507 & 4 & 0.000 & 11.4744 & 11.5662 \\
$|2|$ & -182.222 & $13.684^{*}$ & 4 & 0.008 & $11.3072^{*}$ & $11.4603^{*}$ \\
$|3|$ & -178.539 & 7.3668 & 4 & 0.118 & $11.7437^{*}$ & 11.7561 \\
$|4|$ & -174.872 & 7.3325 & 4 & 0.119 & 11.5258 & 11.3454 \\
\hline
\end{tabular}

Source: Author computation:

Note: * indicate lag order selection by criteria 


\subsection{Cointegration Test Results}

After confirming the stationarity of all variables at $I(1)$, we proceed to examine the issue of cointegration among the variables. Having cointegrating relationship between economic growth and trade openness means, the variables have a common trend and long-run equilibrium.

From Table 5, both trace and maximum eigenvalue criteria indicate the existence of long-run equilibrium relationship between the variables at the 5\% level. As shown in first part of Table 5, no cointegrating relationship between variable is rejected since the trace statistic (29.9600) is greater than the 5\% critical vale (15.41). The same process with maximum eigenvalue statistic the test statistic (29.728) is greater than (14.07) at 5\% critical value. Therefore, we can make a conclusion that there is indeed a long-run dynamic relationship among growth rate of real GDP and trade openness.

Table 5. Johansen co-integration test.

\begin{tabular}{llllll}
\hline Unrestricted Rank co-integration test (Trace) & & & & \\
\hline Maximum rank & Parms & LL & Eigenvalue & Trace statistic & Critical value at 5\% \\
\hline 0 & 6 & -49.6386 & & $29.9600 *$ & 15.41 \\
1 & 9 & -34.7744 & 0.32097 & 0.2315 & 3.76 \\
2 & 10 & -34.6586 & 0.00590 & \\
\hline \multicolumn{7}{l}{ Unrestricted Rank co-integration test (Maximum Eigenvalue) } & & & \\
\hline Maximum rank & Parms & LL & Eigenvalue & Max statistic & Critical value at 5\% \\
\hline 0 & 6 & -49.6386 & & 29.7285 & 14.07 \\
1 & 9 & -34.7744 & 0.56211 & 0.2315 & 3.76 \\
2 & 10 & -34.6586 & 0.00641 & & \\
\hline
\end{tabular}

Source: Author computation

Note: Max-eigenvalue test indicates 1 cointegrationg eqn(s) at the 0.05 level, $*$ denotes rejection of the null hypothesis at $5 \%$ level.

\subsection{Vector Error Correction (VEC) Test Results}

After determining optimal lag length, and number of cointegrating vectors, we proceed to estimate the short run behavior and adjustment to the long run equilibrium, which is represented by vector error correction model (VECM). Now, we estimate VEC model with one lag since we have selected lag two for VAR model. The estimated results of the vector error correction model are presented in Table 6.

Table 6. Vector Error Correction Estimates.

\begin{tabular}{lll|l}
\hline Cointegrating Eq: & CointEq1 & $\begin{array}{l}\text { Standard } \\
\text { error }\end{array}$ & T-Statistic \\
\hline gGDP & 1 & & \\
Opp & -54.08523 & 4.623902 & -11.70 \\
C & 2.36818 & & \\
\hline
\end{tabular}

\begin{tabular}{lll}
\hline Error Correction: & D (GRGDP) & D_(Opp) \\
\hline \multirow{2}{*}{$E C_{t-1}$} & -.7020999 & .002599 \\
& $(.2082562)$ & $(.0026245)$ \\
& $(-3.37)$ & $(0.99)$ \\
$\Delta\left(G R G D P_{t-1}\right)$ & -.0524844 & -.0030851 \\
& $(.1739503)$ & $(.0021922)$ \\
$\Delta\left(O p p_{t-1}\right)$ & $(-0.30)$ & $(-1.41)$ \\
& 0.06799 & -.0912808 \\
& $(0.02895)$ & $(.1987851)$ \\
$\mathrm{C}$ & $(2.34853)$ & $(-0.46)$ \\
& .0000575 & .015528 \\
& $(.5299693)$ & $(.0066789)$ \\
\hline
\end{tabular}

Source: Author computationNote: The upper, middle, and lower figures estimated coefficient, standard error, and t-statistic, respectively.

\subsubsection{VEC Granger Causality/Block Exogeneity Wald Tests Results}

We know that system of equation is subjected to Granger Causality (block exogeneity) test. From Table 7 below, we reject the null of no causality from trade openness to growth rate of real GDP at $1 \%$ level, while we fail to reject no causality from growth rate of real GDP to trade openness. Thus, there is no need to interpret the short-run equations corresponding to trade openness equation, which is exogenous. Therefore, we have only one endogenous variable that is growth rate of real GDP.

Table 7. VEC Granger Causality/Block Exogeneity Wald Tests.

\begin{tabular}{llll}
\hline \multicolumn{2}{l}{ Dependent variable: $\boldsymbol{\Delta} \boldsymbol{g} \boldsymbol{G} \boldsymbol{D} \boldsymbol{P}_{\boldsymbol{t}}$} & \\
\hline Equation Excluded & chi2 & df & Prob>chi2 \\
\hline gGDP Opp & 11.464 & 2 & 0.003 \\
gGDPALL & 11.464 & 2 & 0.003 \\
\hline \multicolumn{4}{l}{} \\
\hline Dependent variable: $\boldsymbol{\Delta} \boldsymbol{O p}_{\boldsymbol{t}}$ & & \\
\hline Equation Excluded & chi2 & Df & Prob>chi2 \\
\hline Opp gGDP & 2.297 & 2 & 0.317 \\
Opp ALL & 2.297 & 2 & 0.317 \\
\hline
\end{tabular}

Source: Author computation

\subsubsection{Long Run Interpretation}

The cointegrating vector is given by:

$$
\hat{\beta}=(1,-54.085)
$$

However, in Johansen long run model, we shall reverse the sign of the long run coefficients. That is multiply the coefficient of the long run model by negative one $(-1)$.

The parameter estimates correspond to the cointegrating coefficients of growth rate of real GDP (normalized to one) and trade openness, in that order. The estimated long run model is given by:

$$
g G D \hat{P}=-2.368+54.0850 p \hat{p}
$$


The coefficient trade openness is statistically significant at $1 \%$ level and has the expected positive sign. Since the tstatistic value for openness (after the sign is reversed) is calculated as dividing the coefficient by standard error is significant and obtained as:

$$
t=\frac{54.08523}{4.623902}=11.70
$$

Thus, the null hypothesis of no co-integration is rejected against the alternative of co-integrating relationship in the model. Thus, the estimated long run model given in the above equation shows the existence of strong direct long-run relationship between trade openness and economic growth in Ethiopia during the study period. On average, a one-unit change in trade openness leads to an increase in growth rate of real GDP by 54.085 in the long run, ceteris paribus. A long-run positive relationship between economic growth and trade openness indicates that there is a positive feedback between foreign trade sector and economic growth. This feedback resulting in a lower current account deficit through improving the export sector, new access foreign intermediate products which is significantly supporting domestic industries through supply of raw material and even an increase consumption which is one of the component of GDP and among the other the benefit of liberalization.

\subsubsection{Short-Run Interpretation}

As we have seen from Table 7 in Block Exogeneity Wald Tests, there causality is running from trade openness (Opp) to economic growth (gGDP). Thus, the short run analysis (interpretation) is unidirectional (from trade openness to economic growth) only. The estimated coefficient of the error correction term $(\alpha=-0.702)$ is negative and statistically significant at the one percent level. This shows that about $70.2 \%$ of the short run disequilibrium in growth rate of real GDP will be adjusted within a year (the same year). The coefficient of the trade openness in the Co-integration equation above is (0.0679). It indicates that if trade openness increases by one unit, then value of growth rate of real GDP will increase by 0.0679 . That is in the short-run changes in trade openness affect economic growth positively.

\subsection{Model Adequacy Checking}

In order to ascertain whether the model provides an adequate fit to the data or not, a test for misspecification should be performed.

\subsubsection{Normality}

Multivariate version of the Jarque Bera tests is used to test the normality of the residuals. It compares the skewness and kurtosis coefficients to those from a normal distribution. The null hypothesis is that the error terms in the model have skewness and kurtosis coefficients corresponding to a normal distribution. The results given in Table 8 show that the null hypothesis of multivariate normality of the residuals cannot be rejected for all tests under consideration
Table 8. Jarque-Bera test.

\begin{tabular}{llll}
\hline Equation & chi2 & Df & Prob>chi2 \\
\hline D_gGDP & 0.279 & 2 & 0.86990 \\
D_Opp & 1.609 & 2 & 0.44732 \\
ALL & 1.888 & 4 & 0.75640 \\
\hline
\end{tabular}

Source: Author computation

\subsubsection{Autocorrelation}

Here we utilize VEC residual serial correlation LM tests. The result of the test is illustrated in Tables 9. The test results show that the null hypothesis of no serial correlation in the residuals cannot be rejected.

Table 9. Lagrange-multiplier test.

\begin{tabular}{llll}
\hline lag & chi2 & Df & Prob>chi2 \\
\hline 1 & 15.1319 & 4 & 0.0644 \\
2 & 2.7316 & 4 & 0.60369 \\
\hline
\end{tabular}

Source: Author's computation

\subsubsection{Model Stability}

A stable VEC model should have the value in modulus less than one. As we have seen from the table below, the value in modulus is less than one. Therefore, the VECM model satisfies the stability condition.

Table 10. Eigenvalue stability condition.

\begin{tabular}{ll}
\hline Eigenvalue & Modulus \\
\hline 1 & 1 \\
0.0258902 & 0.02589 \\
\hline
\end{tabular}

Source: Author's computation. The VECM specification imposes a unit modulus.

\section{Conclusions and Recommendations}

\subsection{Conclusions}

Generally, a continuous and stable economic growth given an opened economy is the main goals of the government's and macroeconomic policy makers. Therefore, it is important to investigate the dynamic relationship between trade openness and growth. To this end, annual data from the period 1982-2019 were used to estimate the dynamic relationship between trade openness and economic growth of Ethiopia.

From the preliminary analysis, both series showed a trending pattern, that is, there is the sign of non-stationarity in both series at level. The ADF and Phillips-Perron tests shows that the series are non-stationary at level, but stationary after first differencing.

The appropriate number of lag identified using different information criteria (AIC, BIC, HQ etc.) is one and hence we should include one lag in cointegration test. From Johansen co integration test, we observe the existence of one co integration vector. Thus, we use a VEC model to estimate the long run relationship between trade openness and economic growth in the country during the study period.

The estimated coefficient of the error correction term (- 
0.702) in growth rate of GDP (since we have one cointegrating equation) was found to be negative and statistically significant at the one percent level. This shows that about $70 \%$ of the short run disequilibrium in growth rate of real GDP will be adjusted within the same year. The estimated long run model shows the existence of strong positive long-run relationship between trade openness and economic growth. As we have seen from Block Exogeneity Wald Tests results, the causality is running only from trade openness to economic growth. Moreover, in the short run, one-time lagged trade openness has a significant positive impact on the current growth rate of real GDP. The model diagnostic result shows normality of the residuals, no autocorrelation and stability condition were satisfied.

\subsection{Recommendations}

Based on the findings, the following recommendations are forwarded to the concerned bodies.

As trade openness has a positive long run effect on growth rate of real GDP in Ethiopia, so the government should promote its trade liberalization policy in order to enhance the economic growth of the country since liberalization helps to allocate resource more efficiently especially for those protected sector through competition. However, it needs strong policy based follow-up.

Moreover, the inclusion of other potential variables such as foreign direct investment, interest rate, money supply, education, and employment leaves a further room for future study as a driver of economic growth in Ethiopia.

\section{Abbreviations}

$\begin{array}{ll}\text { Augmented Dickey-Fuller } & \text { ADF } \\ \text { Error Correction Model } & \text { ECM } \\ \text { Gross Domestic Product } & \text { GDP } \\ \text { Hannan-Quinn Criterion } & \text { HQ } \\ \text { International monetary fund } & \text { IMF } \\ \text { Phillip-Perron } & \text { PP } \\ \text { Structural adjustment program } & \text { SAP } \\ \text { The Akaike Information Criterion } & \text { AIC) } \\ \text { The Bayesin Information Criterion } & \text { BIC } \\ \text { Vector auto regression } & \text { VAR } \\ \text { World Bank } & \text { WB }\end{array}$

\section{Conflicts of Interests}

The authors declare that they have no competing interests.

\section{References}

[1] Romer, P. M. (1990). Endogenous technological change. The Journal of Political Economy, 98 (5), S71-S102.

[2] Bhagwati, J. N. (1990). "Export Promoting Trade Strategy: Issues and Evidence", in Milner.

[3] Dornbusch, R., Fischer, S. and Samuelson, P. (1977).
"Comparative Advantage, Trade and economic growth: The case of Ghana and Nigeria", International Journal of Economics and Economic Journal, vol. 108, 1523-46.

[4] Rodriguez, C. A. (1974). The non-equivalent of tariffs and quota under retaliation. Journal of international economics, vol. 4, pp, 295-98.

[5] Singer, H. (1950). "The Distribution of Gains between Investing and Borrowing Countries".

[6] Prebisch, Y. (1950). "The Economic Development of Latin America and Its Principal.

[7] Thirlwall, A. P. (2000). Trade, Trade Liberalization and Economic Growth: Theory and Evidence. Economic Research Papers (63). University of Kent at Canterbury.

[8] Manni, U. H and Ibne Afzal, M. N. (2012). Effect of Trade Liberalization on Economic Growth of Developing Countries: A Case of Bangladesh Economy. Journal of Business, Economics and Finance Universiti Brunei Darussalam: Brunei. 1 (2).

[9] Almas Heshmati and Yeonhak Kim. (2012). Time series analysis of interdependent phases of the electricityindustry in South Korea. OPEC Energy Review, 36 (3), 319-348.

[10] Mukhopadhay, k. and Chakraborty, D. (2005). Is liberalization of trade good for the environment? Evidence from India. Asia -Pacific Development Journal. 12 (1): 109-139.

[11] Zewdu Bedasa \& Minyahil Alemun. (2017). Economic Growth Nexus Trade Liberalization in Ethiopia: Evidence from the Johnson's Multivariate Cointegration Analysis. International Journal of Latest Research in Engineering and Technology (IJLRET); ISSN: 2454-5031. Vol 03 PP. 53-59.

[12] Salinas, G and Aksoy, A. (2006). Growth Before and After Trade Liberalization. World Bank Policy Research Working Paper (4062).

[13] Gujarati. (2004). "Basic Econometrics", 4thedition, New York: The McGraw-Hill.

[14] Phillips, P., \& Perron, P. (1988). Testing for unit root in time series regression. Biometrika, 75 (2), 335-346. http://dx.doi.org/10.2307/2336182.

[15] Hall, S. G., \& Henry, S. S. B. (1989). Macroeconomic modeling. Amsterdam, The Netherlands: Elsevier SciencePublishers.

[16] Johansen, S. and K. Juselius, (1990). Maximum likelihood estimation and inference on cointegration with application to the demand for money. Oxford Bulletin of Economics and Statistics, 52 (2): 169-210.

[17] Johansen, S. (1988). Statistical Analysis of Cointegrated Vectors, Journal of Economic Dynamics and Control, 12: 231254.

[18] Juselius, K. (2006). The Cointegrated VAR Model: Methodology and Applications, Advanced Texts in Econometrics, Oxford University Press.

[19] Lütkepohl, H. (2005). New Introduction to Multiple Time Series Analysis, Spring Verlag, Berlin.

[20] Alexander, C. (2001). Market models: A guide to financial data analysis. John Wiley \& Sons Ltd and Welfare in an Open Economy, Journal of International Economics, 32: 179-91. 
[21] Granger, C. W. J. (1969). Investing causal relations by econometric models and cross-spectral methods, Econometrica, 37: 424-438.
[22] Lütkepohl, H. (1993). Testing for causation between two variables in higher dimensional VAR models, in $\mathrm{H}$. Schneeweiss and K. F. Zimmermann (eds), Studies in Applied Econometrics, Physica-Verlag, Heidelberg, pp. 75-91. 